\title{
EDITORIAL
}

\section{Inflammation: friend or foe of muscle remodelling in COPD?}

\author{
R.C.J. Langen and A.M.W.J. Schols
}

$\mathbf{A}$ $\mathrm{n}$ enhanced systemic inflammatory response is a typical feature of chronic diseases, including chronic obstructive pulmonary disease (COPD), cancer, rheumatoid arthritis and chronic heart failure. The pattern and degree of systemic cytokine elevation is remarkably comparable among these conditions, despite different primary organ pathology. Interestingly, these diseases share skeletal muscle weakness and wasting as a common phenomenon in the disease course, and experimental studies using different acute and chronic disease models have clearly implicated cytokinemediated effects, particularly of tumour necrosis factor (TNF)- $\alpha$, on muscle contractility and muscle atrophy and regeneration.

TNF- $\alpha$ is thought to act on skeletal muscle cells in an endocrine as well as autocrine/paracrine fashion, but as yet it is unclear whether this cytokine is causally related to (altered) skeletal muscle remodelling and whether its effects facilitate or interfere with muscle plasticity in COPD. One approach to unravelling the role of TNF- $\alpha$ in atrophy, regeneration and muscle fibre type shifting is to compare local expression of TNF- $\alpha$ during muscle remodelling, e.g. in conditions which are accompanied by alterations in skeletal muscle mass, structure or metabolic activity.

Limited studies have investigated TNF- $\alpha$ expression in muscle biopsies of patients with COPD and unfortunately, no studies are yet available comparing expression levels between different muscles within the same subject. Some studies $[1,2]$ have demonstrated elevated muscular TNF- $\alpha$ expression in patients with COPD compared with healthy control subjects, but this finding was not confirmed by other studies $[3,4]$.

Muscle biopsies are generally taken from the lower limb muscle (vastus lateralis). However, GEA et al. [5] were the first to draw attention to differential metabolic and structural adaptations of respiratory and lower and upper limb muscle, which could be related to differences in activity pattern. This "compartments" theory implies that muscular abnormalities obtained from vastus lateralis muscle cannot readily be

Dept of Respiratory Medicine, NUTRIM School for Nutrition, Toxicology and Metabolism, Maastricht University, Maastricht, The Netherlands.

STATEMENT OF INTEREST: None declared.

CORRESPONDENCE: A.M.W.J. Schols, Dept of Respiratory Medicine, NUTRIM School for Nutrition, Toxicology and Metabolism, Maastricht University, Maastricht, The Netherlands. Fax: 31 433075051.E-mail: a.schols@pul.unimaas.nl extrapolated to upper limb or respiratory muscles, in particular in subjects with a sedentary lifestyle or patients with COPD who may suffer from both respiratory and limb muscle weakness. Indeed, a study comparing muscle structure and metabolism demonstrated that the diaphragm in controls and in COPD patients had a higher oxidative potential than the vastus lateralis, and that these muscle adaptations occur earlier in the diaphragm than in the vastus lateralis in mild-tomoderate COPD [6] . These studies are, however, hampered by the fact that it is nearly impossible to collect samples from patients without significant comorbidity and no data are available regarding altered cytokine expression in the diaphragm of patients with COPD. As an alternative approach, in the current issue of the European Respiratory Journal, CASADEvall et al. [7] collected biopsies from the external intercostal muscle that also actively participates in ventilation. Comparison of biopsies of COPD patients and healthy controls revealed increased pro-inflammatory cytokine expression, in particular TNF- $\alpha$, in intercostal muscles of COPD patients.

How may these findings relate to respiratory muscle dysfunction in COPD? Experimental studies have clearly demonstrated that high levels of exogenous or endogenous TNF- $\alpha$ induce contractile dysfunction of diaphragm muscles [8-10]. Conversely, muscular dystrophy-associated diaphragm dysfunction was attenuated in TNF- $\alpha$-deficient mice [11]. In contrast, the actions of TNF- $\alpha$ on limb muscle contractile function are controversial $[9,10]$. In line with the compartments theory, differential responses to inflammatory stimuli between respiratory and limb muscle have been postulated, as basal and lipopolysaccharide-induced inflammatory gene expression was markedly elevated in diaphragm compared with tibialis anterior muscle [12]. Nevertheless, cause and functional consequences of increased TNF- $\alpha$ expression, with respect to altered contractile protein composition and oxidative phenotype commonly observed in respiratory muscles in COPD remain unclear, as few or no studies have investigated the effects of inflammatory mediators on muscle oxidative phenotype.

In the study by CASADEVALL et al. [7], increased proinflammatory cytokine expression in the intercostal muscles of COPD patients was accompanied by a tendency for increased sarcolemmal damage, tempting the authors to speculate that local TNF- $\alpha$ expression may be involved in muscle injury and/or regeneration. TNF- $\alpha$ expression may be cause or consequence of the observed damage, as both beneficial and detrimental effects on muscle regeneration have 
been attributed to TNF- $\alpha$ signalling. In skeletal muscle of myopathy patients, as well as in experimental models, muscle regeneration is associated with increased TNF- $\alpha$ expression [13-16]. However, studies evaluating whether TNF- $\alpha$ expression is required for efficient regeneration using TNF- $\alpha$ or double TNF- $\alpha$ receptor-knockout animals have yielded opposing results $[15,17]$. Similarly, studies in which muscular levels of TNF- $\alpha$ were experimentally increased revealed inhibition [18-21] as well as stimulation [16] of muscle differentiation and regeneration. These apparently contradictory findings may be reconciled by differential effects depending on concentration and duration, as stimulation of differentiation was observed in response to low levels of TNF- $\alpha$, whereas high levels of TNF inhibited regeneration and differentiation in a nuclear factor (NF)- $\mathrm{BB}$-dependent fashion, which involved destabilisation of the myogenic regulatory factor MyoD. Some of the beneficial effects of low levels of TNF- $\alpha$ on regeneration may involve macrophage and neutrophil recruitment, as well as myoblast chemotaxis $[22,23]$.

In addition to effects on regeneration, a substantial amount of experimental studies have demonstrated that peripheral muscle atrophy is induced by and depends on TNF- $\alpha$ and subsequent NF- $\kappa \mathrm{B}$ signalling and muscle protein proteolysis via the 26S-ubiquitin proteasome pathway [18, 21, 24, 25]. Interestingly, OTTENHEIM et al. [26] demonstrated myosinheavy chain depletion in the diaphragm muscle of COPD patients, which, in light of the atrophy-inducing effects of inflammatory signalling, suggests that increased TNF- $\alpha$ expression observed in the study by CASADEVALL et al. [7] may also be involved in atrophy of the respiratory muscles. Based on these findings and the reported increases in TNF- $\alpha$ expression [1] and NF- $\mathrm{B}$ activation [27] in the limb musculature of cachectic COPD patients, anti-TNF- $\alpha$ treatment may appear to be an interesting therapeutic approach. Recently, RENNARD et al. [28] studied the clinical efficacy of infliximab, an anti-TNF- $\alpha$ antibody, in moderate-to-severe COPD. In general, no effects were observed but a post hoc analysis revealed a significant positive effect on 6-min walking distance in the subgroup of cachectic patients.

However, considering the opposing evidence from experimental studies regarding the role of tumour necrosis factor- $\alpha$ and inflammatory signalling in regeneration, it appears that, depending on timing, duration, magnitude and composition of the inflammatory response, muscle regeneration may beneficially or detrimentally be affected by tumour necrosis factor- $\alpha$. Consequently, therapeutic approaches to the restoration or maintenance of muscle function in chronic obstructive pulmonary disease via modulation of tumour necrosis factor- $\alpha$ / inflammatory signalling will require the availability of biomarkers that can provide information regarding the nature of the local inflammatory response in order to prevent interference with aspects of inflammation required for efficient regeneration. Moreover, as the little information available suggests a differential response and sensitivity between respiratory and peripheral muscles to inflammatory cues, a more fundamental understanding of inflammatory signalling in the different types of skeletal muscles is required for the safe targeting of inflammation in order to prevent or restore muscle (dys)function in chronic obstructive pulmonary disease.

\section{REFERENCES}

1 Montes de Oca M, Torres SH, De Sanctis J, Mata A, Hernández N, Tálamo C. Skeletal muscle inflammation and nitric oxide in patients with COPD. Eur Respir J 2005; 26: 390-397.

2 Rabinovich RA, Figueras M, Ardite E, et al. Increased tumour necrosis factor- $\alpha$ plasma levels during moderateintensity exercise in COPD patients. Eur Respir J 2003; 21: 789-794.

3 Koechlin C, Maltais F, Saey D, et al. Hypoxaemia enhances peripheral muscle oxidative stress in chronic obstructive pulmonary disease. Thorax 2005; 60: 834-841.

4 Vogiatzis I, Stratakos G, Simoes DD, et al. Effects of rehabilitative exercise on peripheral muscle TNF- $\alpha$, IL-6, IGF-I and MyoD expression in COPD patients. Thorax 2007; [Epub ahead of print PMID: 17573449].

5 Gea J, Orozco-Levi M, Barreiro E, Ferrer A, Broquetas J. Structural and functional changes in the skeletal muscles of COPD patients: the "compartments" theory. Monaldi Arch Chest Dis 2001; 56: 214-224.

6 Doucet M, Debigaré R, Joanisse DR, et al. Adaptation of the diaphragm and the vastus lateralis in mild-to-moderate COPD. Eur Respir J 2004; 24: 971-979.

7 Casadevall C, Coronell C, Ramírez-Sarmiento AL, et al. Upregulation of pro-inflammatory cytokines in the intercostal muscles of COPD patients. Eur Respir J 2007; 30: 701-707.

8 Wilcox PG, Wakai Y, Walley KR, Cooper DJ, Road J. Tumor necrosis factor alpha decreases in vivo diaphragm contractility in dogs. Am J Respir Crit Care Med 1994; 150: 1368-1373.

9 Li X, Moody MR, Engel D, et al. Cardiac-specific overexpression of tumor necrosis factor- $\alpha$ causes oxidative stress and contractile dysfunction in mouse diaphragm. Circulation 2000; 102: 1690-1696.

10 Reid MB, Lannergren J, Westerblad H. Respiratory and limb muscle weakness induced by tumor necrosis factor- $\alpha$ : involvement of muscle myofilaments. Am J Respir Crit Care Med 2002; 166: 479-484.

11 Gosselin LE, Barkley JE, Spencer MJ, McCormick KM, Farkas GA. Ventilatory dysfunction in mdx mice: impact of tumor necrosis factor- $\alpha$ deletion. Muscle Nerve 2003; 28: 336-343.

12 Demoule A, Divangahi M, Yahiaoui L, et al. Endotoxin triggers nuclear factor- $\mathrm{\kappa B}$-dependent up-regulation of multiple proinflammatory genes in the diaphragm. Am J Respir Crit Care Med 2006; 174: 646-653.

13 Kuru S, Inukai A, Kato T, Liang Y, Kimura S, Sobue G. Expression of tumor necrosis factor $\alpha$ in regenerating muscle fibers in inflammatory and non-inflammatory myopathies. Acta Neuropathol (Berl) 2003; 105: 217-224.

14 Zador E, Mendler L, Takacs V, de Bleecker J, Wuytack F. Regenerating soleus and extensor digitorum longus muscles of the rat show elevated levels of TNF- $\alpha$ and its receptors, TNFR-60 and TNFR-80. Muscle Nerve 2001; 24: 1058-1067.

15 Collins RA, Grounds MD. The role of tumor necrosis factor- $\alpha(\mathrm{TNF}-\alpha)$ in skeletal muscle regeneration. Studies in TNF- $\alpha(-/-)$ and TNF- $\alpha(-/-) / \mathrm{LT}-\alpha(-/-)$ mice. J Histochem Cytochem 2001; 49: 989-1001. 
16 Chen SE, Jin B, Li YP. TNF- $\alpha$ regulates myogenesis and muscle regeneration by activating p38 MAPK. Am J Physiol Cell Physiol 2007; 292: C1660-C1671.

17 Chen SE, Gerken E, Zhang Y, et al. Role of TNF- $(\alpha)$ signaling in regeneration of cardiotoxin-injured muscle. Am J Physiol Cell Physiol 2005; 289: C1179-C1187.

18 Guttridge DC, Mayo MW, Madrid LV, Wang CY, Baldwin AS Jr. NF-кB-induced loss of MyoD messenger RNA: possible role in muscle decay and cachexia. Science 2000; 289: 2363-2366.

19 Langen RC, Schols AM, Kelders MC, Wouters EF, JanssenHeininger YM. Inflammatory cytokines inhibit myogenic differentiation through activation of nuclear factor- $\kappa \mathrm{B}$. FASEB J 2001; 15: 1169-1180.

20 Langen RC, Van Der Velden JL, Schols AM, Kelders MC, Wouters EF, Janssen-Heininger YM. Tumor necrosis factor- $\alpha$ inhibits myogenic differentiation through MyoD protein destabilization. FASEB J 2004; 18: 227-237.

21 Langen RC, Schols AM, Kelders MC, van der Velden JL, Wouters EF, Janssen-Heininger YM. Muscle wasting and impaired muscle regeneration in a murine model of chronic pulmonary inflammation. Am J Respir Cell Mol Biol 2006; 35: 689-696.
22 Peterson JM, Feeback KD, Baas JH, Pizza FX. Tumor necrosis factor- $\alpha$ promotes the accumulation of neutrophils and macrophages in skeletal muscle. J Appl Physiol 2006; 101: 1394-1399.

23 Torrente Y, El Fahime E, Caron NJ, et al. Tumor necrosis factor- $\alpha(\mathrm{TNF}-\alpha)$ stimulates chemotactic response in mouse myogenic cells. Cell Transplant 2003; 12: 91-100.

24 Buck M, Chojkier M. Muscle wasting and dedifferentiation induced by oxidative stress in a murine model of cachexia is prevented by inhibitors of nitric oxide synthesis and antioxidants. EMBO J 1996; 15: 1753-1765.

25 Cai D, Frantz JD, Tawa NE Jr, et al. IKK $\beta / N F-\kappa B$ activation causes severe muscle wasting in mice. Cell 2004; 119: 285-298.

26 Ottenheijm CA, Heunks LM, Sieck GC, et al. Diaphragm dysfunction in chronic obstructive pulmonary disease. Am J Respir Crit Care Med 2005; 172: 200-205.

27 Agusti A, Morla M, Sauleda J, Saus C, Busquets X. NF-кB activation and iNOS upregulation in skeletal muscle of patients with COPD and low body weight. Thorax 2004; 59: 483-487.

28 Rennard SI, Fogarty C, Kelsen S, et al. The safety and efficacy of infliximab in moderate to severe chronic obstructive pulmonary disease. Am J Respir Crit Care Med 2007; 175: 926-934. 